\title{
The association between genetic variants in HSD3B1 and clinical management of PCa
}

\author{
Jingyi Huang', Da Huang ${ }^{1}$, Rong $\mathrm{Na}^{1,2}$ \\ 'Department of Urology, Ruijin Hospital, Shanghai Jiao Tong University School of Medicine, Shanghai 200025, China. \\ ${ }^{2}$ Program for Personalized Cancer Care, NorthShore University HealthSystem, Evanston, IL 60201, USA.
}

Correspondence to: Dr. Rong Na, Department of Urology, Ruijin Hospital, Shanghai Jiao Tong University School of Medicine, 197 Ruijin 2nd Road, Shanghai 200025, China. E-mail: narong.hs@gmail.com; Dr. Da Huang, Department of Urology, Ruijin Hospital, Shanghai Jiao Tong University School of Medicine, 197 Ruijin 2nd Road, Shanghai 200025, China.

E-mail: huangdasjtu@gmail.com

How to cite this article: Huang J, Huang D, Na R. The association between genetic variants in HSD3B1 and clinical management of PCa. J Trans/ Genet Genom 2021;5:240-9. https://dx.doi.org/10.20517/jtgg.2021.14

Received: 13 Mar 2021 First Decision: 25 May 2021 Revised: 7 Jun 2021 Accepted: 11 Jun 2021 First online: 17 Jun 2021

Academic Editor: Sanjay Gupta Copy Editor: Yue-Yue Zhang Production Editor: Yue-Yue Zhang

\begin{abstract}
Androgen is an important factor in the occurrence and progression of prostate cancer. The principal clinical strategy is androgen deprivation therapy (ADT). However, progression to castrate-resistant prostate cancer (CRPC) is almost inevitable to occur after ADT. One of the key mechanisms is the intertumoral synthesis of androgen where $3 \beta$-hydroxysteroid dehydrogenase isoenzyme-1 (3ßHSD1, encoded by HSD3B1) catalyzes the ratelimiting step. A germline missense-encoding variant of HSD3B1(1245A>C, rs1047303) has been the focus of research because HSD3B1(1245C) works as an adrenal-permissive allele and encodes a more stable enzyme that promotes the synthesis of androgen. Several studies were performed to explore the role of HSD3B1(1245C) in the development of CRPC and the outcome of clinical management. Thus, we searched the published research articles using the keywords "prostate cancer" and "HSD3B1", in PubMed and Embase database. After reviewing the abstracts and full articles, 16 original research articles from 45 search results were finally selected and reviewed. Based on the current evidence, HSD3B1(1245C) is proposed to accelerate ADT resistance and the development of CRPC. It is also associated with a poorer prognosis of PCa treated with ADT. However, due to conflicting results, the association between HSD3B1(1245C) and the effect of next-generation hormone therapy (i.e., abiraterone) for patients with CRPC is not clear enough. In conclusion, HSD3B1(1245C) has value for predicting the outcome of PCa and potential to be involved in therapeutic decision making.
\end{abstract}


Keywords: HSD3B1, germline, prostate cancer, androgen deprivation therapy, castration-resistant prostate cancer, abiraterone, predictive biomarker, multienzyme complexes, patient stratification, omics

\section{INTRODUCTION}

It is widely accepted that androgen and androgen receptor (AR) play an important role in the occurrence and progression of prostate cancer $(\mathrm{PCa})^{[1]}$. Androgen deprivation therapy (ADT) via medical or surgical castration, which has been applied since $1941^{[2]}$, is the principal therapeutic strategy to advanced prostate cancer. The general clinical efficiency of ADT depends on its blockage of gonadal androgen ${ }^{[3-5]}$. However, the development from castrate-sensitive prostate cancer (CSPC) to castrate-resistant prostate cancer (CRPC) is eventually inevitable $\mathrm{e}^{[4]}$. One of the key mechanisms is the intertumoral synthesis of androgen, including testosterone and dihydrotestosterone (DHT), which originate from adrenal precursor steroids, such as dehydroepiandrosterone (DHEA) ${ }^{[6,7]}$. The androgen synthesis is considered to induce the reactivation of AR. When the disease finally progresses to the state of CRPC, it becomes highly lethal. To solve this clinical problem, next-generation hormone therapies were introduced nearly a decade ago ${ }^{[8]}$. Since then, the PCa prognosis is noted to be largely improved by several new drugs such as docetaxel (a microtubule inhibitor), abiraterone (a selective inhibitor of cytochrome P450 17A1 (CYP17A1), which is a key enzyme in androgen synthesis), and enzalutamide (a targeted androgen receptor inhibitor ${ }^{[9-11]}$.

In terms of the intertumoral androgen synthesis, several key enzymes and genes in the synthetic process are identified as potential targets for diagnosis or treatment. One of them is $3 \beta$-hydroxysteroid dehydrogenase isoenzyme-1 ( $3 \mathrm{BHSD} 1$, encoded by HSD3B1), which catalyzes the rate-limiting step in the metabolic conversion from DHEA to testosterone and DHT in the adrenal gland ${ }^{[12]}$. A specific germline missenseencoding variant of $\mathrm{HSD} 3 \mathrm{~B} 1(1245 \mathrm{~A}>\mathrm{C}$, rs 1047303) leads to a divergence of enzyme level and downstream androgen synthesis. $\mathrm{HSD}_{3} \mathrm{~B} 1(1245 \mathrm{~A})$ is known as an adrenal-restrictive allele as it codes an enzyme that is degraded more rapidly, while $\mathrm{HSD} 3 \mathrm{~B} 1$ (1245C), an adrenal-permissive allele, codes a stable enzyme resistant to proteasomal degradation that promotes robust conversion from DHEA to DHT ${ }^{[13,14]}$. A series of studies indicated that genetic variants in $\mathrm{HSD}_{3} \mathrm{~B} 1$ are associated with the progression of $\mathrm{PCa}$ and resistance of ADT. In this review, the homozygous variant genotype is referred to as HSD3B1 (CC), while the heterozygous genotype and homozygous wild type are referred to as $\mathrm{HSD}_{3} \mathrm{~B}_{1}(\mathrm{AC})$ and HSD3B1 (AA), respectively.

In this review, we summarize the published studies regarding the association between HSD3B1 and the clinical management of PCa, including both CSPC and CRPC. We also discuss the contemporary significance of $\mathrm{HSD} 3 \mathrm{~B} 1$ and its potential value in the therapeutic decision in $\mathrm{PCa}$.

\section{EVIDENCE SYNTHESIS}

We searched the published research articles using the keywords "prostate cancer" and "HSD3B1", in PubMed and Embase database. In total, 45 results were found. After review of the abstracts and full articles, 16 original research articles were finally included in this review.

\section{HSD3B1(1245C) promotes resistance to ADT and development to CRPC}

Recently, plenty of evidence shows that PCa patients carrying HSD3B1(1245C) variant were more likely to become resistant to ADT and progress to CRPC. This variant was also reported to be associated with worse survival outcome for patients with PCa treated with ADT, especially for those with low-volume diseases. 
As shown in Table 1 , since Ross et al. ${ }^{[15]}$ first reported in 2008 that SNPs rs1870050 in CYP19A1 [hazard ratio $(\mathrm{HR})=0.60 ; P=0.0007], \mathrm{rs} 1856888$ in $\mathrm{HSD} 3 \mathrm{~B} 1(\mathrm{HR}=0.58 ; P=0.0047)$, and rs7737181 in HSD $17 \mathrm{~B} 4$ $(\mathrm{HR}=0.70 ; P=0.0096)$ were related to shorter time to progression, the role of HSD3B1 in PCa has been paid close attention by researchers because $3 \beta \mathrm{HSD} 1$ encoded by HSD3B1 is necessary for the synthesis of non-testicular testosterone or DHT. Wu et al. ${ }^{[16]}$ in 2015 first summarized that HSD3B1(1245C) PCa is more likely to progress to CRPC, according to a retrospective study involving 85 patients with AA genotype and 18 with AC genotype who were diagnosed as advanced PCa and underwent surgical castration. However, no significant disparity of overall survival time was shown related to HSD3B1.

Hearn et al. ${ }^{[17]}$ reported that HSD3B1(1245C) is significantly associated with PCa resistance to ADT. As a multi-cohort study, they enrolled 443 patients treated with ADT after prostatectomy from three cohorts: the post-prostatectomy cohort from the Cleveland Clinic registry, the post-prostatectomy validation cohort from the Mayo Clinic SPORE registry, and the metastatic validation cohort from the Mayo Clinic metastatic prostate cancer registry. The frequency of variant was $26 \%-36 \%$. In the primary cohort, compared with the AA genotype group, the CC genotype groups $(\mathrm{HR}=2.4 ; P=0.029)$ and the AC group $(\mathrm{HR}=1.7 ; P=0.041)$ were associated with worse progression-free survival (PFS). However, in the other two cohorts, CC showed the same significant effect on development to CRPC, while the association between the AC genotype and the progression of CRPC was not significant $(\mathrm{HR}=1.1 ; P=0.38)$. In addition, the variant allele was predictive to a worse overall survival.

Subsequently, a few studies came to similar conclusions. Agarwal et al ${ }^{[18]}$ retrospectively analyzed 102 patients with metastatic CSPC accepting ADT. The frequency of variant was $31 \%$. Compared with the PFS in the AA genotype group, in the CC genotype group, PFS was shorter (11 months vs. 21 months; HR = 2.16; $P=0.046$ ), while that in the AC genotype groups was similar ( 19 months vs. 21 months; $\mathrm{HR}=1.04 ; P=$ 0.86). Shiota et al. ${ }^{[19]}$ also performed an analysis on a primary ADT cohort with 104 Japanese patients of metastatic CSPC where the frequency of variant was $5 \%$. The results shown that patients with the CC genotype and the AC genotype were more likely to be resistant to ADT $(\mathrm{HR}=2.34 ; P=0.03)$ but had no significant difference for mortality.

Hearn et al. ${ }^{[20]}$ furthered their studies on the basis of their original report. Instead of post-prostatectomy, focusing on patients undergoing ADT post-radiotherapy, the study proved that HSD3B1(1245C) was also associated with rapid development of metastases. Furthermore, analyses were performed on the E3805 Chemohormonal Therapy Versus Androgen Ablation Randomized Trial for Extensive Disease in Prostate Cancer cohort which included patients with metastatic PCa undergoing ADT with or without docetaxel. They concluded that HSD3B1(1245C) was related to earlier development of CRPC $(\mathrm{HR}=1.89 ; P=0.02)$ and shorter overall survival $(\mathrm{HR}=1.74 ; P=0.045)$ in patients with low-volume disease but not in patients with high-volume disease $\mathrm{e}^{[21]}$.

The current clinical studies on the role of HSD3B1 in CSPC patients treated with ADT are discussed above. With regard to the effect of HSD3B1 (CC) for accelerating the resistance to ADT and progression to CRPC, the results of current studies are in agreement. A meta-analysis by Han et al. ${ }^{[22]}$ confirmed this conclusion and also concluded that HSD3B1 had no association with mortality. Except the outcome in the primary cohort of the Hearn's study in $2016^{[17]}$, HSD3B1(1245C) was noted to have no impact on the mortality of CSPC. At a more fundamental level, Chen et al. ${ }^{[23]}$ reported that HSD3B1 was marginally significantly associated with impaired survival outcome. Based on the study by Hearn et al..$^{[21]}$, the effect of HSD3B1 was only found in patients with low-volume PCa. It was difficult to derive a precise conclusion from the analysis for the overall cohort. In addition, it is worth noting that the association between the AC genotype and 
Table 1. Summary of studies about the association between HSD3B1 variants and PCa treated with ADT

\begin{tabular}{|c|c|c|c|c|c|}
\hline Study & Medical management & No. of Cases & No. of Carriers & Results & Conclusions \\
\hline Ross et al. ${ }^{[15]}, 2008^{*}$ & ADT & 529 & 62 & $\begin{array}{l}\text { For TTP: } \\
\text { HR }=0.58 ; 95 \% \mathrm{Cl}: 0.41-0.81 ; P=0.0047\end{array}$ & $\begin{array}{l}\text { The polymorphism in HSD3B1 was associated with time to } \\
\text { progression during ADT for } \mathrm{PCa}\end{array}$ \\
\hline Wu et al. ${ }^{[16]}, 2015$ & ADT & 103 & 18 & $\begin{array}{l}\text { For incidence of CRPC: } \\
\text { AC vs. } A A: 100 \% \text { vs. } 64.7 \% ; P=0.003\end{array}$ & Variant HSD3B1 associated higher incidence of CRPC \\
\hline \multirow[t]{3}{*}{ Hearn et al. ${ }^{[17]}, 2016$} & ADT & 118 & 74 & $\begin{array}{l}\text { For PFS: } \\
\text { CC: } \mathrm{HR}=2.4 ; 95 \% \mathrm{Cl}: 1.1-5.3 ; P=0.029 \\
\text { AC: } \mathrm{HR}=1.7 ; 95 \% \mathrm{Cl}: 1.0-2.9 ; P=0.041 \\
\text { For OS: } \\
\text { CC: } \mathrm{HR}=3.3 ; 95 \% \mathrm{Cl}: 1.3-8.3 ; P=0.013 \\
\text { AC: } \mathrm{HR}=2.0 ; 95 \% \mathrm{Cl}: 1.1-3.7 ; P=0.036\end{array}$ & $\begin{array}{l}\text { Patients carrying variant HSD } 3 \mathrm{~B} 1 \text { are more likely to fail } \\
\text { with ADT and to have worse survival outcome }\end{array}$ \\
\hline & ADT & 137 & 60 & $\begin{array}{l}\text { For PFS: } \\
\text { CC: } \mathrm{HR}=2.7 ; 95 \% \mathrm{Cl}: 1.2-5.9 ; P=0.013 \\
\text { AC: } \mathrm{HR}=1.0 ; 95 \% \mathrm{Cl}: 0.7-1.7 ; P=0.085\end{array}$ & \\
\hline & ADT & 188 & 90 & $\begin{array}{l}\text { For OS: } \\
\text { CC: } \mathrm{HR}=2.5 ; 95 \% \mathrm{Cl}: 1.2-5.0 ; P=0.013 \\
\text { AC: } \mathrm{HR}=1.5 ; 95 \% \mathrm{Cl}: 1.0-2.1 ; P=0.036\end{array}$ & \\
\hline Agarwal et al. ${ }^{[18]}, 2017$ & ADT & 102 & 52 & $\begin{array}{l}\text { For PFS: } \\
\text { CC: } \mathrm{HR}=2.16 ; 95 \% \mathrm{Cl}: 1.01-4.58 ; P=0.046 \\
\text { AC: } \mathrm{HR}=1.04 ; 95 \% \mathrm{Cl}: 0.64-1.07 ; P=0.86\end{array}$ & $\begin{array}{l}\text { HSD3B1 genotype CC but not AC, was associated with } \\
\text { shorter PFS }\end{array}$ \\
\hline Hearn et al. ${ }^{[20]}, 2018$ & ADT after radiotherapy & 218 & 116 & $\begin{array}{l}\text { For time to metastasis: } \\
C C: \mathrm{HR}=2.01 ; 95 \% \mathrm{Cl}: 1.02-3.97 ; P=0.045 \\
\text { AC: } \mathrm{HR}=1.19 ; 95 \% \mathrm{Cl}: 0.74-1.92 ; P=0.48 \\
\text { No significant differences in TTP or OS }\end{array}$ & $\begin{array}{l}\text { Variant HSD3B1 was associated with shorter time to } \\
\text { metastasis but not with death and progression risk }\end{array}$ \\
\hline Shiota et al. ${ }^{[19]}, 2019$ & ADT & 104 & 9 & $\begin{array}{l}\text { For PFS: } \\
\text { CC } / A C: H R=2.34 ; 95 \% C l: 1.08-4.49 ; P=0.03 \\
\text { For OS: } \\
\text { CC } / A C: H R=1.36 ; 95 \% C l: 0.52-2.92 ; P=0.50\end{array}$ & $\begin{array}{l}\text { Variant HSD3B1 was associated with shorter PFS but not } \\
\text { with death risk }\end{array}$ \\
\hline Hearn et al. ${ }^{[21]}, 2020$ & $\begin{array}{l}\text { ADT randomized plus } \\
\text { docetaxel }\end{array}$ & 475 & 270 & $\begin{array}{l}\text { For PFS: } \\
\text { In low-volume disease group: } \\
\text { CC/AC: } \mathrm{HR}=1.89 ; 95 \% \mathrm{Cl}: 1.13-3.14 ; P=0.02 \\
\text { In high-volume disease group: } \\
\text { CC/AC: } \mathrm{HR}=1.10 ; 95 \% \mathrm{Cl}: 0.82-1.47 ; P=0.52 \\
\text { For OS: } \\
\text { In low-volume disease group: } \\
\text { CC/AC: } \mathrm{HR}=1.74 ; 95 \% \mathrm{Cl}: 1.01-3.00 ; P=0.045 \\
\text { In high-volume disease group: } \\
\text { CC/AC: } \mathrm{HR}=0.89 ; 95 \% \mathrm{Cl}: 0.65-1.22 ; P=0.48\end{array}$ & $\begin{array}{l}\text { Variant HAD3B1 was associated with higher risk of } \\
\text { progression and death for patients with low-volume } \\
\text { disease, but not with high-volume }\end{array}$ \\
\hline Chen et al. ${ }^{[23]}, 2020$ & ADT & 101 & 42 & $\begin{array}{l}\text { For OS: } \\
\text { CC } / A C \text { vs. AA: } 5.0 \text { years vs. } 6.5 \text { years; } P=0.052\end{array}$ & $\begin{array}{l}\text { Variant HSD3B1 was marginally significantly associated } \\
\text { with shorter OS }\end{array}$ \\
\hline
\end{tabular}

${ }^{\star}$ Except for the study by Ross et al. ${ }^{[15]}$ (rs1856888), all other studies investigated the variant rs1047303. ADT: Androgen deprivation therapy; TTP: time to progression; HR: hazard ratio; 95\%Cl: 95\% confidence interval; CRPC: castrate-resistant prostate cancer; PFS: progression-free survival; OS: overall survival. 
survival outcome remains unclear. The effect of the AC genotype on promoting resistance to ADT was statistically significant in only one study ${ }^{[17]}$. In contrast, in the other two cohorts of Hearn's study in 2016 and the cohort in Agarwal's study, no difference in overall survival was observed between the AC and AA genotype groups.

\section{Impact of HSD3B1(1245C) on the other medical management is waiting to define}

Since the function of germline variants in HSD3B1 was confirmed to promote the development of resistance to ADT, several works focused on how it influences the outcome when coming to the state of CRPC. It has been reported that HSD3B1(1245C) might have a negative effect on the overall survival of CRPC. However, there are contradictions in the existing results about its association with the response to medical management, such as abiraterone and enzalutamide, in the state of CRPC.

Stangl-Kremser et al. ${ }^{[24]}$ and Chen et al. ${ }^{[23]}$ both summarized the association between HSD3B1(1245C) and survival outcome of patients with CRPC via genetic sequencing of prostate tissue. The former concluded that there was no relation between HSD3B1(1245C) and survival outcome of CRPC ${ }^{[24]}$. Similarly, the latter reported that $\mathrm{HSD} 3 \mathrm{~B} 1(1245 \mathrm{C})$ was related to a trend of worse prognosis for CRPC because of increased tumor expression of cell proliferation and cell cycle genes ${ }^{[23]}$, but without significant difference.

It is not clear whether HSD3B1(1245C) induces an impaired survival outcome in the state of CRPC. It would also be valuable to explore if germline HSD3B1 is predictive for the reaction to the related medical management for CRPC. Hearn et al. ${ }^{[21]}$ reported no relation between HSD3B1 and response to docetaxel. In addition, as mentioned above, the key mechanism of CRPC development is intertumoral androgen synthesis and reactivation of AR. Some medical therapies aiming at blocking this process, known as AR pathway inhibitors (ARPIs), are widely accepted to be applied in the treatment of CRPC, such as AR antagonists including enzalutamide and CYP17A1 inhibitors including 17 $\alpha$-hydroxylase/17,20-lyase. In addition, CYP17A1 inhibitors include nonsteroidal and steroidal types. Steroidal CYP17A1 inhibitors, such as abiraterone, are converted by $3 \beta \mathrm{HSD} 1$, the downstream metabolites of which act as AR agonists, inducing an opposite effect ${ }^{[25,26]}$.

Biologically, HSD3B1(1245C) is supposed to invalidate both abiraterone and enzalutamide. Alyamani et al. ${ }^{[27]}$ [Table 2] conducted a study on the pharmacokinetics and metabolites of the steroidal CYP17A1 inhibitor abiraterone. They concluded that HSD3B1 might negate the efficiency of abiraterone based on the results that the downstream metabolite of abiraterone, 3-keto-5 $\alpha$-abiraterone, which is an AR agonist, significantly increased with more copies of HSD3B1(1245C), while the level of another metabolite, $\mathrm{D} 4 \mathrm{~A}$, which is an AR antagonist, did not increase. Theoretically, in addition to abiraterone, enzalutamide may also be negated by HSD3B1(1245C). The permissive adrenal effect of HSD3B1(1245C) causes an increase of testosterone. It has been reported that increased the AR natural ligand might decrease the activity of enzalutamide ${ }^{[28]}$.

Several clinical studies were performed to identify the role of HSD3B1. Almassi et al ${ }^{[29]}$ focused on the relation between $\mathrm{HSD}_{3} \mathrm{~B} 1$ and the curative effect of the nonsteroidal CYP17A1 inhibitor ketoconazole among patients with metastatic CRPC. They concluded that HSD3B1(1245C) marginally significantly prolonged time of progression. Compared with the AA genotype group, the HR of the AC genotype group for disease progression was $0.6(P=0.06)$ and the HR of the CC genotype group was $0.5(P=0.08)$. Hahn et al. ${ }^{[30]}$ focused on the predictive effect of HSD3B1(1245C) for patients with CRPC treated with abiraterone as first-line therapy, showing that there were no significant associations. 
Table 2. Summary of studies about the association between HSD3B1 variants and PCa treated with other medical management

\begin{tabular}{|c|c|c|c|c|c|}
\hline Study & $\begin{array}{l}\text { Medical } \\
\text { management }\end{array}$ & $\begin{array}{l}\text { No. of } \\
\text { Cases }\end{array}$ & $\begin{array}{l}\text { No. of } \\
\text { Carriers }\end{array}$ & Results & Conclusions \\
\hline Almassi et al. ${ }^{[29]}, 2018$ & Ketoconazole & 90 & 46 & $\begin{array}{l}\text { For duration of treatment: } \\
\text { CC: } \mathrm{HR}=2.2 ; 95 \% \mathrm{Cl}: 1.1-4.4 ; P= \\
0.02 \\
\text { AC: } \mathrm{HR}=1.8 ; 95 \% \mathrm{Cl}: 1.1-2.9 ; P= \\
0.01 \\
\text { For disease progression: } \\
\text { CC: } \mathrm{HR}=0.5 ; 95 \% \mathrm{Cl}: 0.3-1.1 ; P= \\
\text { O.08 } \\
\text { AC: } \mathrm{HR}=0.6 ; 95 \% \mathrm{Cl}: 0.4-1.0 ; P \\
=0.06\end{array}$ & $\begin{array}{l}\text { The HSD3B1(1245C) variant allele is } \\
\text { associated with prolonged time to disease } \\
\text { progression among men with metastatic } \\
\text { CRPC treated with nonsteroidal CYP17A1 } \\
\text { inhibition }\end{array}$ \\
\hline Hahn, et al. ${ }^{[30]}, 2018$ & Abiraterone & 76 & 34 & $\begin{array}{l}\text { For PFS: } \\
\text { CC vs. AA: } 6.4 \text { m vs. } 7.3 \mathrm{~m} ; P= \\
0.28 \\
\text { CA vs. AA: } 6.2 \text { m vs. } 7.3 \mathrm{~m} ; P= \\
0.64\end{array}$ & $\begin{array}{l}\text { Variant HSD3B1 caused no difference with } \\
\text { the response to abiraterone }\end{array}$ \\
\hline Shiota et al. ${ }^{[19]}, 2019$ & Abiraterone & 99 & 14 & $\begin{array}{l}\text { For treatment failure: } \\
\text { AC: } \mathrm{HR}=0.35 ; 95 \% \mathrm{Cl}: 0.13- \\
0.80 ; P=0.01 \\
\text { For } \mathrm{OS}: \\
\text { AC: } \mathrm{HR}=0.40 ; 95 \% \mathrm{Cl}: 0.13- \\
0.94 ; P=0.04\end{array}$ & $\begin{array}{l}\text { Variant HSD3B1 was associated with less } \\
\text { treatment failure and better survival } \\
\text { outcome for CRPC treated with abiraterone }\end{array}$ \\
\hline Hearn et al. ${ }^{[21]}, 2020$ & $\begin{array}{l}\text { ADT randomized } \\
\text { plus docetaxel }\end{array}$ & 475 & 270 & Data not shown & $\begin{array}{l}\text { Variant HSD3B1 did not appear to be } \\
\text { predictive of differential benefit with } \\
\text { docetaxel }\end{array}$ \\
\hline Khalaf et al.[31], 2020 & $\begin{array}{l}\text { Abiraterone or } \\
\text { enzalutamide }\end{array}$ & 546 & 297 & $\begin{array}{l}\text { For TTP: } \\
\text { CC: HR = 1.31; 95\%Cl: } 1.02-1.67 ; \\
P=0.032 \\
\text { For PSA response: } \\
\text { CC vs. AC vs. AA: } 48 \% \text { vs. } 62 \% \\
\text { vs. } 65 \% ; P=0.019 \\
\text { For TTPP: } \\
\text { CC: HR = } 1.28 ; 95 \% \mathrm{Cl}: 0.99-1.66 ; \\
P=0.064\end{array}$ & $\begin{array}{l}\text { HSD3B1 (CC) was associated with shorter } \\
\text { TTP and less response rate, but not with } \\
\text { survival outcome }\end{array}$ \\
\hline Lu et al. ${ }^{[32]}, 2020$ & $\begin{array}{l}\text { Abiraterone or } \\
\text { enzalutamide }\end{array}$ & 266 & 123 & $\begin{array}{l}\text { For PSA30 response: } \\
\text { CC vs. AC/AA: } 67.7 \% \text { vs. } 68.4 \% ; \\
P>0.99 \\
\text { For duration of treatment: } \\
\text { CC: } \mathrm{HR}=1.25 ; 95 \% \mathrm{Cl}: 0.79-1.97 ; \\
P=0.34 \\
\text { For OS: } \\
\text { CC: } \mathrm{HR}=1.78 ; 95 \% \mathrm{Cl}: 1.03-3.07 ; \\
P=0.04\end{array}$ & $\begin{array}{l}\text { HSD3B1 (CC) was associated with shorter } \\
\text { overall survival, but not with response to } \\
\text { treatment }\end{array}$ \\
\hline
\end{tabular}

HR: Hazard ratio; 95\% CI: 95\% confidence interval; CRPC: castrate-resistant prostate cancer; PFS: progression-free survival; OS: overall survival; TTP: time to progression; PSA: prostate specific antigen.

Both Khalaf etal. ${ }^{[31]}$ and Lu et al. ${ }^{[32]}$ investigated the association between HSD3B 1 and abiraterone/enzalutamide. In the work of Khalaf et al. ${ }^{[31]}, 547$ patients from two cohorts were involved. For patients with metastatic CRPC treated with abiraterone/enzalutamide, the CC genotype had worse time to progression $(\mathrm{HR}=1.31 ; P=0.032)$ and a nonsignificant trend to shorter time to PSA progression $(\mathrm{HR}=$ 1.28; $P=0.064)$. In addition, the CC genotype was less likely to achieve a PSA response according to the PSA response rates ( $48 \%$ for CC, $62 \%$ for AC, and $65 \%$ for AA, $P=0.019$ ). However, no association was shown between HSD3B1(1245C) and overall survival. In contrast, Lu et al. ${ }^{[32]}$ proposed that HSD3B1 (CC) was related to worse survival outcome $(\mathrm{HR}=1.78 ; P=0.04)$ and had no association with response to management in patients with $\mathrm{MCRPC}$ treated with abiraterone/enzalutamide according to the analysis of a cohort of 266 patients. 
Shiota et al.$^{[19]}$ reported a completely opposite conclusion based on a cohort of 99 Japanese patients with CRPC using abiraterone. Patients carrying variant genotypes (CC or AC) had significantly lower progression risk $(\mathrm{HR}=0.32 ; P=0.006)$ and lower all-cause mortality risk $(\mathrm{HR}=0.40 ; P=0.04)$ compared with others carrying the AA genotype. Furthermore, Shiota et al. ${ }^{[33]}$ also studied the combinational use of HSD3B1 and $5 \alpha$-reductase (encoding by SRD5A2), a key enzyme for conversion of testosterone into DHT. They showed that HSD3B1 (AA) with variant genotype of SRD5A2 led to the worst response to abiraterone in the state of CRPC.

In summary, germline variants of HSD3B1 influence the therapeutic effects of patients with CRPC, especially for abiraterone and enzalutamide. However, there exists a contradiction with regard to the exact function. Further studies are necessary to figure out the role of HSD3B1.

\section{Potential role of the HSD3B1 in the clinical management of PCa}

Based on the published studies, the role of germline HSD3B1(1245C) in PCa is summarized as follows: (1) in the state of CSPC, HSD3B1(1245C) accelerates resistance to ADT, especially for patients with lowvolume diseases; (2) for the survival outcome of patients with CSPC undergoing ADT, evidence of the impact of HSD3B1(1245C) is not sufficient; (3) in the state of CRPC, HSD3B1(1245C) affects the efficiency of clinical management but cannot be a reliable biomarker because of conflicting results; and (4) for the survival outcome of patients with CRPC, $\mathrm{HSD} 3 \mathrm{~B} 1(1245 \mathrm{C})$ probably has a negative effect.

Although how HSD3B1 functions is still not clear, the HSD3B1 genotype can still provide some advice for clinical management. For patients with advanced PCa receiving ADT, HSD3B1 variant genotypes can remind physicians to pay more attention to the progression of resistance to ADT. When choosing other medical therapies, germline variants of $\mathrm{HSD} 3 \mathrm{~B} 1$ can act as a reference according to current studies.

Additionally, further studies are worth performing to demonstrate the effect of HSD3B1 variants on clinical management of PCa. In theory, HSD3B1(1245C), as an adrenal-permissive allele, is considered to induce a switch to a reduced tumor dependence on gonadal androgens and augmented dependence on extragonadal androgens. According to the study by Khalaf et al. ${ }^{[13]}$, the treatment effect and survival outcome were more favorable in the cohort where ARPIs were used as first-line therapy than other cohorts where previous firstline therapies were allowed. These two facts suggest that using ARPIs in the state of CSPC might benefit patients carrying HSD3B1 variants. In recent years, abiraterone with ADT was also shown to improve the prognosis of $\mathrm{CSPC}^{[34,35]}$. As a result, a predictive role of $\mathrm{HSD} 3 \mathrm{~B} 1$ variants for abiraterone used in the state of CSPC is a potential topic of further research.

Besides, some points provide potential directions for future study in order to identify the association between $\mathrm{HSD} 3 \mathrm{~B} 1$ and the clinical management of PCa. First, HSD3B1 variants present a significant interethnic disparity. For example, the frequency of HSD3B1(1245C) is $34 \%$ for European, $20 \%$ for American, $16 \%$ for South Asian, 9\% for African, and $8 \%$ for East Asian patients ${ }^{[36]}$. Inter-ethnic disparity may be one of the explanations to the opposite outcomes about the effect of HSD3B1(1245C) on abiraterone. Second, loss of heterozygosity $(\mathrm{LOH})$ is presented in the HSD3B1 gene. Hearn et al. ${ }^{[17]}$ observed that 3 of $11(27 \%)$ patients with $\mathrm{HSD} 3 \mathrm{~B} 1$ (AC) had developed CRPC with $\mathrm{LOH}$ of the wild-type allele, whereas none had lost the variant allele. This observation might explain the better treatment outcome when ARPIs were used as first-line therapy. Third, Hearn et al. ${ }^{[2]}$ concluded that the influence of HSD3B1 depends on the tumor burden (the extent of metastatic disease), which might be worth in-depth study. At last, it remains to be studied whether HSD3B1 can be treated as a therapeutic target for PCa, about which no work has been reported up to now. However, the therapeutic potential of targeting HSD3B1 was reported in triple-negative 
breast cancer based on an in vitro study ${ }^{[37]}$.

\section{CONCLUSION}

HSD3B1(1245C) has been found to be associated with ADT resistance and poorer prognosis. Its association with next-generation hormone therapy is still unclear (i.e., abiraterone). Very few commercial genetic profiling products have included this variant in routine testing. However, its clinical impact as well as its high cost-effectiveness (single variant testing is usually inexpensive) should not be underestimated. Based on the review of the current evidence, clinicians should consider a more aggressive treatment or follow-up strategy for patients with HSD3B1(1245C) variants who are undergoing ADT.

\section{DECLARATIONS}

\section{Authors' contributions}

Conception and design: Na R, Huang D, Huang J

Literature review: Huang J, Huang D

Manuscript writing: Na R, Huang D, Huang J

All authors contributed to the article and approved the final version.

\section{Availability of data and materials}

Not applicable.

\section{Financial support and sponsorship}

None.

\section{Conflicts of interest}

All authors declared that there are no conflicts of interest.

\section{Ethical approval and consent to participate}

Not applicable.

\section{Consent for publication}

Not applicable.

\section{Copyright}

(c) The Author(s) 2021.

\section{REFERENCES}

1. Scher HI, Halabi S, Tannock I, et al; Prostate Cancer Clinical Trials Working Group. Design and end points of clinical trials for patients with progressive prostate cancer and castrate levels of testosterone: recommendations of the Prostate Cancer Clinical Trials Working Group. J Clin Oncol 2008;26:1148-59. DOI PubMed

2. Huggins C, Hodges CV. Studies on prostatic cancer. I. The effect of castration, of estrogen and androgen injection on serum phosphatases in metastatic carcinoma of the prostate. CA Cancer J Clin 1972;22:232-40. DOI PubMed

3. Pagliarulo V. Androgen deprivation therapy for prostate cancer. Adv Exp Med Biol 2018;1096:1-30. DOI PubMed

4. Harris WP, Mostaghel EA, Nelson PS, Montgomery B. Androgen deprivation therapy: progress in understanding mechanisms of resistance and optimizing androgen depletion. Nat Clin Pract Urol 2009;6:76-85. DOI PubMed PMC

5. Teo MY, Rathkopf DE, Kantoff P. Treatment of Advanced Prostate Cancer. Annu Rev Med 2019;70:479-99. DOI PubMed PMC

6. Karantanos T, Evans CP, Tombal B, Thompson TC, Montironi R, Isaacs WB. Understanding the mechanisms of androgen deprivation resistance in prostate cancer at the molecular level. Eur Urol 2015;67:470-9. DOI PubMed PMC

7. Sharifi N. Minireview: Androgen metabolism in castration-resistant prostate cancer. Mol Endocrinol 2013;27:708-14. DOI PubMed PMC

8. Nuhn P, De Bono JS, Fizazi K, et al. Update on systemic prostate cancer therapies: management of metastatic castration-resistant prostate cancer in the era of precision oncology. Eur Urol 2019;75:88-99. DOI PubMed

9. Davis ID, Martin AJ, Stockler MR, et al; ENZAMET Trial Investigators and the Australian and New Zealand Urogenital and Prostate 
Cancer Trials Group. Enzalutamide with standard first-line therapy in metastatic prostate cancer. N Engl J Med 2019;381:121-31. DOI PubMed

10. Chi KN, Agarwal N, Bjartell A, et al; TITAN Investigators. Apalutamide for metastatic, castration-sensitive prostate cancer. $N$ Engl $J$ Med 2019;381:13-24. DOI PubMed

11. Fizazi K, Scher HI, Molina A, et al. Abiraterone acetate for treatment of metastatic castration-resistant prostate cancer: final overall survival analysis of the COU-AA-301 randomised, double-blind, placebo-controlled phase 3 study. Lancet Oncol 2012;13:983-92. DOI PubMed

12. Evaul K, Li R, Papari-Zareei M, Auchus RJ, Sharifi N. 3beta-hydroxysteroid dehydrogenase is a possible pharmacological target in the treatment of castration-resistant prostate cancer. Endocrinology 2010;151:3514-20. DOI PubMed

13. Chang KH, Li R, Kuri B, et al. A gain-of-function mutation in DHT synthesis in castration-resistant prostate cancer. Cell 2013;154:1074-84. DOI PubMed PMC

14. Naelitz BD, Sharifi N. Through the looking-glass: reevaluating DHEA metabolism through HSD3B1 genetics. Trends Endocrinol Metab 2020;31:680-90. DOI PubMed PMC

15. Ross RW, Oh WK, Xie W, et al. Inherited variation in the androgen pathway is associated with the efficacy of androgen-deprivation therapy in men with prostate cancer. J Clin Oncol 2008;26:842-7. DOI PubMed

16. Wu G, Huang S, Nastiuk KL, et al. Variant allele of HSD3B1 increases progression to castration-resistant prostate cancer. Prostate 2015;75:777-82. DOI PubMed PMC

17. Hearn JWD, Abuali G, Reichard CA, et al. HSD3B1 and resistance to androgen-deprivation therapy in prostate cancer: a retrospective, multicohort study. Lancet Oncol 2016;17:1435-44. DOI PubMed

18. Agarwal N, Hahn AW, Gill DM, Farnham JM, Poole AI, Cannon-Albright L. Independent validation of effect of HSD3B1 genotype on response to androgen-deprivation therapy in prostate cancer. JAMA Oncol 2017;3:856-7. DOI PubMed PMC

19. Shiota M, Narita S, Akamatsu S, et al. Association of missense polymorphism in HSD3B1 with outcomes among men with prostate cancer treated with androgen-deprivation therapy or abiraterone. JAMA Netw Open 2019;2:e190115. DOI PubMed

20. Hearn JWD, Xie W, Nakabayashi M, et al. Association of HSD3B1 genotype with response to androgen-deprivation therapy for biochemical recurrence after radiotherapy for localized prostate cancer. JAMA Oncol 2018;4:558-62. DOI PubMed PMC

21. Hearn JWD, Sweeney CJ, Almassi N, et al. HSD3B1 genotype and clinical outcomes in metastatic castration-sensitive prostate cancer. JAMA Oncol 2020;6:e196496. DOI PubMed PMC

22. Han FF, Ren LL, Xuan LL, et al. HSD3B1 variant and androgen-deprivation therapy outcome in prostate cancer. Cancer Chemother Pharmacol 2021;87:103-12. DOI PubMed

23. Chen WS, Feng EL, Aggarwal R, et al. Germline polymorphisms associated with impaired survival outcomes and somatic tumor alterations in advanced prostate cancer. Prostate Cancer Prostatic Dis 2020;23:316-23. DOI PubMed PMC

24. Stangl-Kremser J, Lemberger U, Hassler MR, et al. Prevalence and prognostic value of the polymorphic variant $1245 \mathrm{~A}>\mathrm{C}$ of HSD3B1 in castration-resistant prostate cancer. Clin Genitourin Cancer 2019;17:389-94. DOI PubMed

25. Li Z, Bishop AC, Alyamani M, et al. Conversion of abiraterone to D4A drives anti-tumour activity in prostate cancer. Nature 2015;523:347-51. DOI PubMed PMC

26. Lee BH. Commentary on: "Redirecting abiraterone metabolism to fine-tune prostate cancer anti-androgen therapy." Li Z, Alyamani M, Li J, Rogacki K, Abazeed M, Upadhyay SK, Balk SP, Taplin ME, Auchus RJ, Sharifi N. Nature 2016;533:547-51. Urol Oncol 2017;35:576. DOI PubMed

27. Alyamani M, Emamekhoo H, Park S, et al. HSD3B1(1245A $>$ C) variant regulates dueling abiraterone metabolite effects in prostate cancer. J Clin Invest 2018;128:3333-40. DOI PubMed PMC

28. Richards J, Lim AC, Hay CW, et al. Interactions of abiraterone, eplerenone, and prednisolone with wild-type and mutant androgen receptor: a rationale for increasing abiraterone exposure or combining with MDV3100. Cancer Res 2012;72:2176-82. DOI PubMed PMC

29. Almassi N, Reichard C, Li J, et al. HSD3B1 and Response to a nonsteroidal CYP17A1 inhibitor in castration-resistant prostate cancer. JAMA Oncol 2018;4:554-7. DOI PubMed PMC

30. Hahn AW, Gill DM, Nussenzveig RH, et al. Germline variant in HSD3B1 (1245 A > C) and response to abiraterone acetate plus prednisone in men with new-onset metastatic castration-resistant prostate cancer. Clin Genitourin Cancer 2018;16:288-92. DOI PubMed

31. Khalaf DJ, Aragón IM, Annala M, et al; PROREPAIR-B investigators. HSD3B1 (1245A >C) germline variant and clinical outcomes in metastatic castration-resistant prostate cancer patients treated with abiraterone and enzalutamide: results from two prospective studies. Ann Oncol 2020;31:1186-97. DOI PubMed

32. Lu C, Terbuch A, Dolling D, et al. Treatment with abiraterone and enzalutamide does not overcome poor outcome from metastatic castration-resistant prostate cancer in men with the germline homozygous HSD3B1 c.1245C genotype. Ann Oncol 2020;31:1178-85. DOI PubMed

33. Shiota M, Akamatsu S, Narita S, et al. The association between missense polymorphisms in SRD5A2 and HSD3B1 and treatment failure with abiraterone for castration-resistant prostate cancer. Pharmacogenomics J 2021. DOI PubMed

34. Fizazi K, Tran N, Fein L, et al; LATITUDE Investigators. Abiraterone plus prednisone in metastatic, castration-sensitive prostate cancer. N Engl J Med 2017;377:352-60. DOI PubMed

35. Fizazi K, Tran N, Fein L, et al. Abiraterone acetate plus prednisone in patients with newly diagnosed high-risk metastatic castrationsensitive prostate cancer (LATITUDE): final overall survival analysis of a randomised, double-blind, phase 3 trial. Lancet Oncol 2019;20:686-700. DOI PubMed 
36. Sabharwal N, Sharifi N. HSD3B1 Genotypes conferring adrenal-restrictive and adrenal-permissive phenotypes in prostate cancer and beyond. Endocrinology 2019;160:2180-8. DOI PubMed PMC

37. Chang YC, Lin CH, Lin JC, Cheng SP, Chen SN, Liu CL. Inhibition of $3 \beta$-hydroxysteroid dehydrogenase type 1 suppresses Interleukin-6 in breast cancer. J Surg Res 2019;241:8-14. DOI PubMed 